\title{
Cenário dos repositórios institucionais: a realidade dos Institutos Federais de Educação, Ciência e Tecnologia
}

\author{
Scenario of institutional repositories: the reality of the Federal Institutes of Education, \\ Science and Technology
}

\begin{abstract}
Vera Lucia Solano Feitosa Porto
Mestranda em Educação Profissional e Tecnológica pelo Instituto Federal de Educação, Ciência e Tecnologia de

Mato Grosso do Sul - IFMS, Brasil.

Bibliotecária-documentalista do Instituto Federal de Educação, Ciência e Tecnologia de Mato Grosso do Sul -

IFMS, Brasil.

https://orcid.org/0000-0003-1806-5825

E-mail: vera.porto@ifms.edu.br
\end{abstract}

Vanessa Oliveira de Macêdo Cavalcanti

Doutoranda em Ciência da Informação pela Universidade Federal de Santa Catarina - UFSC, Brasil. Bibliotecária-documentalista do Instituto Federal de Educação, Ciência e Tecnologia do Rio Grande do Norte -

IFRN, Brasil.

http://orcid.org/0000-0001-6976-8470

E-mail: vanessa.cavalcanti@ifrn.edu.br

Bruna Laís Campos do Nascimento

Doutoranda em Ciência da Informação pela Universidade Federal de Pernambuco - UFPE, Brasil. Bibliotecária-documentalista do Instituto Federal de Educação, Ciência e Tecnologia do Rio Grande do Norte -

IFRN, Brasil.

http://orcid.org/0000-0001-6612-2076

E-mail: bruna.campos@ifrn.edu.br

\begin{abstract}
Dante Alighieri Alves de Mello Doutorado em Educação pela Universidade Federal de Mato Grosso do Sul - UFMS, Brasil. Professor do Instituto Federal de Educação, Ciência e Tecnologia de Mato Grosso do Sul - IFMS, Brasil.

E-mail: dante.mello@ifms.edu.br
\end{abstract}

Edgar Bisset Alvarez Doutor em Ciência da Informação pela Universidade Estadual Paulista - UNESP, Brasil. Professor do Programa de pós-graduação em Ciência da Informação da Universidade Federal de Santa Catarina -

UFSC, Brasil.

https://orcid.org/0000-0002-5388-5944

E-mail: edgar.bisset@ufsc.br

\section{Resumo}

Como forma de ampliar a visibilidade e divulgação das produções acadêmicas e científicas, algumas instituições de ensino passaram a fazer uso de Repositórios Institucionais (RI), ferramentas tecnológicas que surgiram a partir do movimento mundial de acesso aberto à informação científica. Este trabalho apresenta como objeto de estudo o cenário de implantação de Repositórios nos Institutos Federais de Educação, Ciência e Tecnologia (IF) com marco temporal até maio de 2020. Trata-se de uma pesquisa bibliográfica e descritiva de caráter qualitativo. Foi realizado o mapeamento para identificar quais IF possuíam Repositório Institucional (RI). A coleta de dados aconteceu por meio de consulta em sites institucionais, envio de e-mails ao grupo de bibliotecários da Rede brasileira de Institutos Federais e coleta de informações por meio do Sistema Eletrônico do Serviço de Informação ao Cidadão (e-SIC). Identificou-se que das 38 instituições pesquisadas 15 já possuem RI e outras 15 estão em fase de implantação. Conclui-se que a implantação de repositórios nos IF ainda precisa avançar significativamente para proporcionar maior visibilidade às suas produções acadêmicas, técnicas e científicas.

Palavras-chave: Repositório Institucional. Acesso Aberto. Produção científica. Institutos Federais de Educação. Rede Federal.

InCID: R. Ci. Inf. e Doc., Ribeirão Preto, v. 12, n. 2, p. 218-238, set. 2021./fev. 2022.

DOI: 10.11606/issn.2178-2075.v12i2p218-238 


\begin{abstract}
In order to expand the visibility and dissemination of academic and scientific output, some educational institutions started to make use of Institutional Repositories (IR), technological tools that emerged from the global movement of open access to scientific information. This work presents as object of study the scenario of Repositories implementation in the Federal Institutes of Education, Science and Technology (IF) with a timeframe up to May 2020. This is a qualitative bibliographic and descriptive research. A mapping was carried out to identify which IF had an Institutional Repository. The data collection happened by consulting institutional websites, sending emails to the group of librarians of the Brazilian Network of Federal Institutes and collecting information through the Electronic System of the Citizen Information Service (e-SIC). It was found that of the 38 institutions surveyed 15 already have an Institutional Repository and another 15 are in the implementation phase. The results show that the implementation of repositories in FIs still needs to advance significantly to provide greater visibility to their academic, technical, and scientific productions.
\end{abstract}

Keywords: Institutional Repository. Open access. Scientific production. Federal Education Institutes. Federal Network.

\title{
1. Introdução
}

A necessidade de acesso à informação tem se tornado cada vez mais imprescindível diante do mundo globalizado em que vivemos. Desde o surgimento da internet e com os avanços constantes das Tecnologias de Informação e Comunicação (TIC), tornou-se possível o acesso a inúmeras informações nos mais diversos formatos, independentemente do lugar físico. Com isso, é fundamental que se criem mecanismos de coleta, organização, gerenciamento, preservação e disponibilização da informação em meio digital. Nesta perspectiva, a partir das iniciativas do Movimento do Acesso Aberto, de profissionais do campo da Ciência da Informação e de áreas afins, começam a se desenvolver estratégias em benefício da Ciência Aberta, em favor da democratização do acesso ao conhecimento científico.

No que diz respeito ao movimento do Acesso Aberto, é importante lembrar que esse movimento possibilitou há algum tempo a origem de duas vias conhecidas mundialmente para acesso ao conhecimento científico: a via verde, que se relaciona à criação dos repositórios institucionais, e a via dourada, que é representada pelos periódicos científicos de acesso aberto (SANTOS; ROSA, 2020).

Inserido neste movimento, que nos últimos anos vem ampliando os diálogos a respeito da importância do acesso à produção científica para todos, estão os Institutos Federais de Educação, Ciência e Tecnologia (IF) pertencentes à Rede Federal de Educação Profissional, Científica e Tecnológica (RFEPCT), que é composta por: 38 Institutos Federais, 2 Centros Federais de Educação Tecnológica (CEFET), a Universidade Tecnológica Federal do Paraná 
(UTFPR), 24 escolas técnicas vinculadas às universidades federais e o Colégio Pedro II (BRASIL, 2008).

A partir da promulgação da Lei no 11.892, de 29 de dezembro de 2008 (BRASIL, 2008), que instituiu a criação dos IF, observou-se que houve um crescimento exponencial dos IF com a implementação do Plano de Expansão e Interiorização da Rede Federal, iniciado no ano de 2005, que revogou ${ }^{1}$ a proibição de criação de novas unidades de ensino profissional em território brasileiro. Com isso, demonstrou-se que o estado brasileiro estava se fazendo presente nas mais diversas regiões, tais como capitais, periferias e até mesmo nas regiões mais remotas do país, uma vez que os Institutos Federais são distribuídos em diversos campi nos respectivos estados. Além disso, a expansão dos IF possibilitou a oferta de uma educação considerada de qualidade a um número maior de pessoas, enquanto que são poucas as redes estaduais de ensino garantindo esse direito, ainda que seja responsabilidade desses entes estatais garantir a universalização do acesso ao ensino médio (MOURA; LIMA FILHO; SILVA, 2015).

Como parte de um projeto societário de governo, a expansão e interiorização de unidades de ensino permitiu a classes desprovidas o acesso ao ensino gratuito e de qualidade. Conforme dados extraídos do Portal do Ministério da Educação (MEC), a Rede Federal de Educação passou de 144 unidades, em 2006, e atingiu no ano de 2019 o quantitativo de 661 unidades de ensino no país.

Com esta expansão, compreende-se que surgem nestes espaços de ensino, pesquisa e extensão um volume de informações técnicas, acadêmicas e científicas, geradas a partir do aumento do número de ofertas de cursos técnicos, superiores e de pós-graduação, do investimento no desenvolvimento de pesquisas e de estudos construídos por meio da ampliação de grupos de pesquisa. Assim, buscando dar mais visibilidade a estas produções e torná-las disponíveis à sociedade, bem como aos pesquisadores e demais membros das próprias instituições é que se justifica a necessidade de estas iniciarem a implantação de seus RI.

Deste modo, mediante tais considerações, o principal objetivo deste artigo é apresentar o cenário de implantação dos RI no âmbito dos IF, com marco temporal até maio de 2020. Para tanto, foi necessário identificar os IF do país, mapear a situação dos RI nos Institutos Federais e verificar os softwares utilizados para o gerenciamento dos RI nos Institutos Federais.

\footnotetext{
${ }^{1}$ A Lei $n^{\circ} 11.195$, de 18 de novembro de 2005, revoga o $§ 5^{\circ}$ do Art. $3^{\circ}$ da Lei no 8.948 , de 8 de dezembro de 1994.
} 
A presente pesquisa caracteriza-se como de caráter descritivo e, para o alcance dos objetivos propostos, utilizou-se como percurso metodológico, a revisão de literatura, a consulta a sites institucionais, o envio de $e$-mails para a coleta de dados e solicitações de informações por meio do Sistema Eletrônico do Serviço de Informação ao Cidadão (e-SIC).

Este estudo faz parte de um projeto de pesquisa do Mestrado Profissional em Educação Profissional e Tecnológica (ProfEPT) em andamento no Instituto Federal de Educação, Ciência e Tecnologia de Mato Grosso do Sul (IFMS), cujo objetivo é implantar o software DSpace ${ }^{2}$, como projeto experimental de repositório digital no Campus Coxim do IFMS, visando analisar a viabilidade, interesse e motivação por parte de determinados usuários desse campus, de modo que possa apresentar subsídios à gestão do IFMS na implantação de um RI de uso geral na instituição.

Um dos desdobramentos institucionais desta pesquisa resultou, em 2019, na instituição de uma Comissão de Trabalho do Repositório Institucional (RI) do IFMS, por meio da Portaria $\mathrm{n}^{\circ} 1359$, de 4 de dezembro de 2019, emitida pela Reitoria, com prazo de um ano, devendo a citada comissão apresentar relatório final à Pró-Reitoria de Ensino (Proen), conforme Boletim de serviço da instituição de $n^{\circ}$ 65/2019, publicado em 6 de dezembro de 2019 (IFMS, 2019).

Além da pesquisa de mestrado acima citada, foram identificados mais dois trabalhos acadêmicos no âmbito do IFMS a respeito de RI. Porto (2016) elaborou um trabalho de conclusão de curso (TCC) em um curso de Biblioteconomia intitulado: "Proposta de implantação de Repositório Institucional no Campus Campo Grande do IFMS: um estudo de caso". Mais recentemente, Fretes e Silva (2019) apresentaram o TCC: "Desenvolvimento do RIF: Repositório institucional de produções científicas e intelectuais do IFMS”, para conclusão do Curso Técnico em Informática no Campus Ponta Porã do IFMS. Esse último trabalho tinha como objetivo o desenvolvimento de um RI para o IFMS.

\footnotetext{
${ }^{2}$ O software DSpace está disponível para download em https://github.com/ibict-br2/repositorio-padrao/. Esse software é gratuito e ao ser adotado pelas organizações, transfere a elas a responsabilidade com as atividades de arquivamento e publicação da sua produção institucional.
} 


\section{Referencial teórico}

A informação sempre se fez presente no cotidiano das pessoas e sua importância se apresenta a cada era, nas mais diversas denominações dadas aos períodos temporais. Reportando-se sobre a presença e relevância da informação ao longo dos anos, vale mencionar que a relação da informação com o ser humano se dá por meio das manifestações próprias da natureza e da interação dos indivíduos. Devido a sua importância nos últimos tempos, a informação passou a ser considerada como fundamental nos mais diversos setores da sociedade e, a partir disso, os períodos temporais passaram a ser denominados associando-se o termo informação, tal como, sociedade da informação, era da informação entre outras (TOMAÉL, 2012).

As produções científicas, mais especificamente, passaram a ser acessadas nesse novo cenário não somente pela classe acadêmica ou por pesquisadores, mas também pelos nãocientistas, pois os computadores e a internet permitiram que a informação científica se tornasse acessível a mais pessoas. Do mesmo modo, a comunicação eletrônica passou a progredir ainda mais. Assim, diante dessas mudanças, os periódicos científicos e repositórios digitais possuem grande relevância para a comunicação científica (CORRÊA, 2017).

Porém, esse processo de produção e divulgação das publicações científicas nem sempre foi facilitado, pois as editoras possuem um controle de difusão das produções, normalmente comercializadas a um custo considerável às bibliotecas e/ou aos pesquisadores diretamente. Segundo Setenareski, Shima e Sunye (2019), o que alterou esse cenário foi o movimento do software livre, que, ao desdobrar-se em outros movimentos e iniciativas, proporcionou aos pesquisadores novas maneiras de publicar e disponibilizar os resultados de suas pesquisas aberta e gratuitamente.

Dessa forma, o movimento em prol do acesso aberto à informação foi um evento histórico importante para a democratização científica. Historicamente, em 1999, houve a Convenção de Santa Fé, nos Estados Unidos, que apontou diretrizes importantes para o acesso aberto por meio da Open Archives Iniciative (OAI). Na sequência, em 2002, a Declaração de Budapeste deu origem ao Budapeste Open Access Initiative (BOAI), por meio da qual ficaram definidos dois tipos de acesso aberto à informação científica: 
a) Acesso Aberto Dourado: baseado nos esforços da comunidade científica para produzir uma nova geração sustentada de periódicos eletrônicos sem cobrança de assinaturas ou taxas;

b) Acesso Aberto Verde: baseado no depósito do texto do artigo submetido a um periódico em um repositório institucional pelo próprio autor - seja a primeira versão seja a versão final já com a revisão pelos pares - conforme as orientações da política editorial da revista a que o autor submeteu o artigo. (WEITZEL, 2019, p. 106).

Além da declaração de Budapeste, destacam-se as declarações de Bethesda e Berlim. A primeira promoveu a discussão do acesso aberto na comunidade de pesquisadores da área Biomédica. Já a segunda, intitulada Berlin Declaration on Open Access to Knowledge in the Sciences and Humanities, recomenda aos pesquisadores que publiquem seus trabalhos com base na filosofia do movimento do acesso aberto (SILVA; ALCARÁ, 2009).

Após essas iniciativas, as ações em favor do acesso aberto à informação científica passaram a ter maior destaque em espaços importantes, como as instituições de ensino e pesquisa. Estas ações são capazes de beneficiar tanto os usuários como as instituições que decidem adotar e estimular o acesso aberto, sejam elas públicas ou privadas. Dentre um dos benefícios do movimento de acesso aberto é possível vislumbrar uma maior visibilidade às pesquisas, uma vez que disponibiliza o conhecimento sem barreiras impostas historicamente ao processo de comunicação científica.

Esse novo cenário propiciou a criação e desenvolvimento de softwares de gestão de repositórios, ferramenta tecnológica que possibilitou a organização, gerenciamento, preservação e disponibilização da produção intelectual de uma instituição. A partir do desenvolvimento dos softwares de código aberto torna-se possível ampliar as estratégias do acesso aberto como, por exemplo, na implementação dos repositórios digitais. Cerrao e Castro (2018, p. 95) conceituam repositório digital como “[...] ambientes de tecnologia aberta, provedores de acesso livre a documentos eletrônicos, que gerenciam, armazenam e disseminam a informação digital.” Segundo mostra a literatura, o repositório digital pode ser dividido em várias classificações, mas neste trabalho se faz referência à classificação definida pelos autores acima citados, na qual divide-se em Repositório Temático (RT) e Repositórios Institucionais (RI). Em síntese, o RT abrange determinada área do conhecimento ou assunto. Já os RI são responsáveis por gerenciar exclusivamente a produção intelectual de uma instituição (CERRAO; CASTRO, 2018).

Os RI aparecem nesse cenário como ferramentas importantes às instituições, pois servem para a organização, preservação e disponibilização do acesso aberto às produções 
acadêmicas, científicas e intelectuais, uma vez que reúne, em um único local/sistema, toda a produção institucional, independentemente do tipo e formato.

Além disso, vale mencionar os impactos culturais, sociais e econômicos causados pela disponibilização dessas produções em uma comunidade. Isso porque essas novas plataformas auxiliam na promoção de aquisição do conhecimento por qualquer pessoa, bem como na possibilidade de geração de mais conhecimento por parte da sociedade, que poderá usufruir desses conteúdos científicos.

O RI surge como um modelo para divulgação e comunicação da produção científica, principalmente nas instituições de ensino, por meio da utilização das estruturas tecnológicas que elas já dispõem. As instituições de ensino subsidiadas por meio de recursos públicos, ao disponibilizarem sua produção acadêmica, científica e intelectual por meio de um RI, estariam cumprindo parte do seu compromisso social com a sociedade, que contribui financeiramente para a sua manutenção e desenvolvimento. Corroborando com esse aspecto social positivo de um RI, os autores Cerrao e Castro (2018, p. 95) ressaltam que:

Os repositórios institucionais garantem às universidades e instituições de pesquisa $o$ acesso livre e gratuito ao conhecimento produzido por seus próprios pesquisadores, definindo-se como alternativa justa e transparente de comunicação científica.

Essas produções, por sua vez, podem proporcionar uma relação direta entre a informação e o avanço social, independentemente do status de conhecimento de quem busca tais informações, seja cientista ou não-cientista. Corrêa (2017, p. 22) relata que: “[...] os nãocientistas também se interessam por ciência, o que traz interesse não somente por resultados estritamente científicos, mas por uma ciência aplicada e próxima à realidade, como produções técnicas e tecnológicas".

Além disso, por meio da implantação de um RI, vislumbra-se a possibilidade de ampliar a visibilidade dos trabalhos técnicos e científicos produzidos nas instituições de ensino, o que poderá auxiliar na promoção e no desenvolvimento de novas pesquisas.

Em relação às vantagens de um RI destaca-se a possibilidade mais ágil de divulgação dos resultados das pesquisas, tornando o acesso rápido, a um custo menor e para um maior número de pessoas e instituições (GRÁCIO, 2012). Além disso, o RI pode se configurar como um método eficiente de preservação da produção científica e intelectual produzida na instituição ou mesmo externamente. 
O Instituto Brasileiro de Informação em Ciência e Tecnologia (IBICT) considera que os repositórios digitais podem ser uma inovação no gerenciamento da informação digital, pois editoras, bibliotecas, arquivos e centros de informação em diversos países estão criando grandes repositórios de informação digital, contendo diferentes tipos de conteúdos e formatos de arquivos digitais (IBICT, 2020).

Vale destacar que no ano de 2004 o IBICT apresentou a versão brasileira customizada do $D_{S p a c e^{3}}$ e, a partir disso, passou a recomendar a utilização desse software para as instituições no país. Tal iniciativa representou um marco pioneiro no desenvolvimento e customização do software para o gerenciamento das produções técnico-científicas no ambiente digital (IBICT, 2020). A partir disso, o IBICT, segundo Weitzel (2019, p. 108),

promoveu diversas ações com o objetivo de implementar a infraestrutura necessária para apoiar e promover o acesso aberto em larga escala e de forma integrada em conformidade com os modelos existentes e amplamente adotados no mundo todo.

Nesse sentido, em 2009, a fim de apoiar a gestão, publicação e o armazenamento em meio digital de publicações científicas, a Financiadora de Inovação e Pesquisa (Finep) do Ministério da Ciência, Tecnologia e Inovações (MCTI), em convênio com o IBICT, lançou dois editais públicos que previam a disponibilização de kits tecnológicos. Cada pacote possuía um servidor e softwares necessários para a implementação de repositórios e do sistema de publicação digital, estando contidos o DSpace e outros softwares livres. No primeiro edital foram contempladas com o kit tecnológico 27 instituições de ensino superior e de pesquisa e, em um segundo edital, 33 instituições (WEITZEL, 2019). É importante salientar que dentre as instituições beneficiadas com esse aporte tecnológico não foi identificado nenhum Instituto Federal.

Em relação ao RI nos IF, Pinto et al. (2019) desenvolveram uma pesquisa, realizada de 2 a 9 de abril de 2019, em que foi constatado que $32 \%$ dos IF possuem RI, cinco estavam em fase de implantação e cinco em estudos iniciais. Os autores identificaram que a falta de gestão e a ausência de conhecimento sobre a importância de um RI são os fatores que podem influenciar as instituições na implantação ou não de um RI.

É preciso deixar claro que, atualmente, as instituições de ensino implantam seu RI de modo facultativo, ou seja, por si só elas decidem organizar e disponibilizar sua produção

${ }^{3}$ O DSpace possui natureza operacional específica de preservar objetos digitais, iniciativa de grande interesse da comunidade científica (IBICT, 2020). 
acadêmica, técnica e científica na web. Portanto, fica a critério da instituição a implantação ou não de um RI.

Por outro lado, em meio a essa situação, surgiram iniciativas legislativas com o intuito de regular as instituições de ensino público a divulgarem sua produção técnico-científica. Em 21 de maio de 2007 foi registrado, na Câmara dos Deputados, o Projeto de Lei (PL) n ${ }^{\circ}$ 1120/2007, com a finalidade de dispor sobre o processo de disseminação da produção científica pelas instituições públicas de ensino superior no país, sendo o Brasil o primeiro país latino a instituir um marco legal (BRASIL, 2007; ALVES, 2017). O PL foi aprovado pela Comissão de Constituição e Justiça e de Cidadania (CCJC), porém em 31 de janeiro de 2012 foi arquivado com fulcro na norma do Art. 15 do Regimento Interno da Câmara dos Deputados:

Finda a legislatura, arquivar-se-ão todas as proposições que no seu decurso tenham sido submetidas à deliberação da Câmara e ainda se encontrem em tramitação, bem como as que abram crédito suplementar, com pareceres ou sem eles [...]. (BRASIL, 1989).

No ano de 2011 foi apresentado o Projeto de Lei do Senado (PLS) no 387/2011, que dispõe sobre o processo de registro e disseminação da produção técnico-científica pelas instituições de educação superior, bem como as unidades de pesquisa no Brasil. Como justificativa, o referido PLS previa que a construção dos repositórios digitais e o arquivamento da produção técnico-científica poderia possibilitar maior visibilidade e transparência dos investimentos do governo em Ciência e Tecnologia (C\&T), além de contribuir, aos poderes públicos, para a elaboração da política de fomento de C\&T para o país (BRASIL, 2011). Entretanto, assim como o PL n 1120/2007, o PLS nº 387/2011 foi arquivado em decorrência do final da Legislatura.

Em 2013 houve outra tentativa legislativa de regular a divulgação da produção técnicocientífica por meio do PL n ${ }^{\circ}$ 6702/2013. Este PL dispõe sobre a existência de repositórios digitais nas instituições federais de educação superior e de pesquisa para gestão e disseminação de sua produção científica, técnica e artística (BRASIL, 2013). Quanto à sua tramitação, consta no site da Câmara dos Deputados que o PL nº 6702/2013 foi arquivado em janeiro de 2019 devido ao fim da legislatura. No entanto, no mês de fevereiro de 2019, o referido PL foi desarquivado. Em seguida, foi encaminhado para a Comissão de Educação (CE), sendo o último trâmite registrado em março de 2019 e, como não foram apresentadas emendas, encerrou-se o prazo. 
Ainda sobre as iniciativas legislativas para formalizar a divulgação de produções acadêmicas e científicas de instituições, apresenta-se como a mais recente, o PLS nº 6473/2019 que sugere alterações nas Leis $n^{\circ}$ 9.394, de 20 de dezembro de 1996 e $\mathrm{n}^{\circ}$ 9.610, de 19 de fevereiro de 1998, para dispor sobre a publicidade dos trabalhos acadêmicos de conclusão de curso na educação superior. A citada proposta de lei estabelece que é responsabilidade das instituições de ensino superior estipular as condições e termos da divulgação e formas de organização, trazendo como exemplos: anuários, coletâneas, livros temáticos, entre outros.

No entanto, mesmo a PLS n ${ }^{\circ}$ 6473/2019 considerando a autonomia da instituição quanto à forma de disponibilização das produções, o documento do Instituto Nacional de Estudos e Pesquisas Educacionais Anísio Teixeira (Inep), que orienta quanto à autorização, o reconhecimento e a renovação de cursos em seu indicador 1.11, para alcance do conceito 5,0, estabelece que o Trabalho de Conclusão de Curso (TCC) precisa estar disponível e acessível em RI próprios (INEP, 2017).

Sobre as proposições de lei que estejam em curso, Alves (2017) explica que isso não exclui a necessidade de debate e instituição da política, tendo em vista que somente isso não é o suficiente, tornando indispensável um compromisso maior das instituições e autoridades que constituem a comunidade científica brasileira, a fim de em comum acordo encontrarem caminhos que possibilitem a disponibilização de suas produções científicas à comunidade em geral.

\section{Procedimentos metodológicos}

Para o desenvolvimento deste trabalho foi feita uma pesquisa descritiva, do tipo bibliográfica, com abordagem qualitativa. Como o objetivo deste artigo é apresentar o cenário dos Institutos Federais quanto à situação dos RI, procedeu-se a revisão de literatura acerca das temáticas abordadas. Em seguida, iniciou-se um levantamento das instituições pertencentes à Rede Federal, identificando os 38 IF como objeto de estudo.

Para a coleta de dados procedeu-se à consulta dos sites institucionais de todos os IF com o intuito de localizar informações sobre a existência de RI e, em caso positivo, obter o endereço eletrônico.

Em seguida, considerando que por meio da visita aos sites não foi possível identificar 
um número expressivo de RI disponíveis, procedeu-se ao envio de e-mails com questionamentos para os profissionais integrantes do Google Groups da Comissão Brasileira de Bibliotecas das Instituições da Rede Federal de Educação Profissional, Científica e Tecnológica (CBBI). Nesta segunda tentativa foram obtidas 27 respostas.

Ainda que a adesão de respondentes na CBBI tenha sido de uma amostragem representativa (cerca de $71 \%$ ) e considerando que buscou-se realizar uma consulta censitária, optou-se por consultar via e-mail as coordenações, diretorias e, eventualmente pró-reitorias, cujos RI estivessem vinculados hierarquicamente na instituição. Contudo, as consultas por $e$ mail e análise dos sites não foram suficientes para a integralidade de informações sobre todos os IF. Deste modo, decidiu-se formalizar os questionamentos aos IF por meio do Sistema Eletrônico do Serviço de Informação ao Cidadão (e-SIC) àquelas instituições que não tinham enviado resposta. Nesse sistema foram registrados 11 pedidos de informações ${ }^{4}$, os quais foram sendo respondidos dentro dos prazos estipulados pela Lei $\mathrm{n}^{\circ} 12.527 / 2011$, de Acesso à Informação, finalizando a coleta total em maio de 2020.

A partir disso iniciou-se a tabulação, análise e interpretação dos dados coletados, que serão apresentados no capítulo seguinte. A análise foi sistematizada em três categorias: (1) identificação dos 38 IF quanto à situação dos RI, isto é, em funcionamento, em implantação e os que ainda não possuíam; (2) organização por frequência em cada uma das cinco regiões do país dos Institutos Federais com RI em funcionamento; (3) identificação e análise dos softwares de gestão de RI utilizados pelos IF.

\section{Resultados e interpretação}

Para o mapeamento dos RI dos Institutos Federais, primeiramente foi necessário identificar os IF pertencentes à Rede Federal. Esta informação foi coletada diretamente no Portal do MEC, recuperando o total de 38 Institutos Federais. Foram identificados 15 RI em funcionamento nos IF, correspondendo a 39,5\% das instituições. No entanto, para melhor compreensão do cenário, dividimos o mapeamento incluindo as informações de instituições que

\footnotetext{
${ }^{4}$ Por meio do e-Sic foram solicitadas as seguintes informações: i) se o IF possuía RI; ii) caso a instituição possuísse, qual era o endereço eletrônico para acesso ao RI; e iii) qual software foi adotado para implantação do respectivo RI.
}

InCID: R. Ci. Inf. e Doc., Ribeirão Preto, v. 12, n. 2, p. 218-238, set. 2021./fev. 2022. 
Vera Lucia Solano Feitosa Porto, Vanessa Oliveira de Macêdo Cavalcanti, Bruna Laís Campos do Nascimento, Dante Alighieri Alves de Mello e Edgar Bisset Alvarez Cenário dos repositórios institucionais: a realidade dos Institutos Federais de Educação, Ciência e Tecnologia

estão em fase de implantação e aquelas que ainda não iniciaram o desenvolvimento de um RI, como mostrado no quadro 1.

Quadro 1 - Mapeamento dos IF quanto à situação do RI.

\begin{tabular}{|c|c|c|c|c|c|}
\hline $\mathbf{N}^{\mathbf{o}}$ & INSTITUTO FEDERAL & SIGLA & $\begin{array}{l}\text { Não } \\
\text { há }\end{array}$ & Implantação & Funcionamento \\
\hline 01 & Instituto Federal do Acre & IFAC & & $\mathrm{X}$ & \\
\hline 02 & Instituto Federal de Alagoas & IFAL & & $\mathrm{X}$ & \\
\hline 03 & Instituto Federal do Amapá & IFAP & & $X$ & \\
\hline 04 & Instituto Federal do Amazonas & IFAM & & & $\mathrm{X}$ \\
\hline 05 & Instituto Federal da Bahia & IFBA & & $\mathrm{X}$ & \\
\hline 06 & Instituto Federal Baiano & IFBaiano & & $X$ & \\
\hline 07 & Instituto Federal do Ceará & IFCE & $\mathrm{X}$ & & \\
\hline 08 & Instituto Federal de Brasília & IFB & & $\mathrm{X}$ & \\
\hline 09 & Instituto Federal do Espírito Santo & IFES & & & $\mathrm{X}$ \\
\hline 10 & Instituto Federal de Goiás & IFG & & & $\mathrm{X}$ \\
\hline 11 & Instituto Federal Goiano & IFGoiano & & & $\mathrm{X}$ \\
\hline 12 & Instituto Federal de Mato Grosso & IFMT & & $\mathrm{X}$ & \\
\hline 13 & Instituto Federal do Maranhão & IFMA & $\mathrm{X}$ & & \\
\hline 14 & Instituto Federal de Mato Grosso do Sul & IFMS & & $\mathrm{X}$ & \\
\hline 15 & Instituto Federal do Sul de Minas & IFSULDEMINAS & & $X$ & \\
\hline 16 & Instituto Federal de Minas Gerais & IFMG & & $\mathrm{X}$ & \\
\hline 17 & Instituto Federal do Norte de Minas & IFNMG & $\mathrm{X}$ & & \\
\hline 18 & Instituto Federal Sudeste de Minas Gerais & IF Sudeste MG & & $\mathrm{X}$ & \\
\hline 19 & Instituto Federal do Triângulo Mineiro & IFTM & $\mathrm{X}$ & & \\
\hline 20 & Instituto Federal do Pará & IFPA & & $\mathrm{X}$ & \\
\hline 21 & Instituto Federal da Paraíba & IFPB & & & $\mathrm{X}$ \\
\hline 22 & Instituto Federal do Paraná & IFPR & $\mathrm{X}$ & & \\
\hline 23 & Instituto Federal de Pernambuco & IFPE & & & $\mathrm{X}$ \\
\hline 24 & Instituto Federal do Sertão Pernambucano & $\begin{array}{c}\text { IF Sertão } \\
\text { Pernambucano }\end{array}$ & & & $X$ \\
\hline 25 & Instituto Federal do Piauí & IFPI & & & $\mathrm{X}$ \\
\hline 26 & Instituto Federal Fluminense & IFF & & & $\mathrm{X}$ \\
\hline 27 & Instituto Federal do Rio de Janeiro & IFRJ & & & $\mathrm{X}$ \\
\hline 28 & Instituto Federal do Rio Grande do Norte & IFRN & & & $\mathrm{X}$ \\
\hline 29 & Instituto Federal Sul-Rio-Grandense & IFSul & & & $\mathrm{X}$ \\
\hline 30 & Instituto Federal do Rio Grande Do Sul & IFRS & & $\mathrm{X}$ & \\
\hline 31 & Instituto Federal Farroupilha & IFFar & & $\mathrm{X}$ & \\
\hline 32 & Instituto Federal de Rondônia & IFRO & & $\mathrm{X}$ & \\
\hline 33 & Instituto Federal de Roraima & IFRR & $\mathrm{X}$ & & \\
\hline 34 & Instituto Federal de São Paulo & IFSP & $\mathrm{X}$ & & \\
\hline 35 & Instituto Federal de Santa Catarina & IFSC & & & $\mathrm{X}$ \\
\hline 36 & Instituto Federal Catarinense & IFC & & & $\mathrm{X}$ \\
\hline 37 & Instituto Federal de Sergipe & IFS & & & $\mathrm{X}$ \\
\hline 38 & Instituto Federal de Tocantins & IFTO & $\mathrm{X}$ & & \\
\hline \multicolumn{3}{|c|}{$\begin{array}{ll}\text { TOTAL } \\
\end{array}$} & 8 & 15 & 15 \\
\hline
\end{tabular}

Fonte: os Autores.

Conforme apresentado no quadro 1 , quanto aos IF que se encontram em fase de implantação do RI, observou-se que 15 institutos $(39,5 \%)$ já iniciaram o processo de implantação. A presente informação se configura como um fator positivo, pois percebe-se que as instituições demonstram interesse em disponibilizar sua produção acadêmica e científica em um futuro breve. Com relação aos IF que ainda não começaram a implantação de seus RI, foram 
identificadas oito instituições, correspondendo a 21\%. Deste quantitativo, foi informado pelos gestores do IFCE e IFTO que existe a intenção de utilizar um sistema de automação de bibliotecas para o gerenciamento das produções intelectuais institucionais.

Sobre os dados acima, é relevante retomar que foram considerados os IF que estão com RI em funcionamento, os que estão em fase de implantação e ainda os que não iniciaram o desenvolvimento do RI. Durante a análise dos dados verificou-se que o Instituto Federal Fluminense (IFF) possui RI em funcionamento que disponibiliza as produções do Campus Campos Centro, além das produções da Editora Essentia do IFF. Embora o RI do IFF esteja compreendido especificamente no Campus Campos Centro, compreende-se nesta pesquisa que há um RI em funcionamento.

No caso do IFMS, mais especificamente, além da pesquisa de mestrado em andamento, foram identificados mais dois trabalhos acadêmicos a respeito da implantação de RI na instituição, conforme já mencionado. Porto (2016) realizou um estudo de caso de uma proposta de implantação de RI no Campus Campo Grande do IFMS. Recentemente, Fretes e Silva (2019) desenvolveram e testaram um RI como TCC no Curso Técnico em Informática do Campus Ponta Porã do IFMS.

A seguir, na tabela 1 , são apresentados os dados que indicam a quantidade de IF divididos por região geográfica no país, o quantitativo de RI em funcionamento por regiões e o percentual entre o número de instituições que possuem RI e o número total de RI por região.

Tabela 1 - Institutos Federais por região com RI em funcionamento.

\begin{tabular}{|l|c|c|c|}
\hline \multicolumn{1}{|c|}{ REGIÃO } & IF & \multicolumn{1}{c}{ RI } & PERCENTUAL RI/IF \\
\hline Nordeste & 11 & 6 & $54,5 \%$ \\
\hline Sul & 6 & 3 & $50,0 \%$ \\
\hline Sudeste & 9 & 3 & $33,3 \%$ \\
\hline Centro-Oeste & 5 & 2 & $40,0 \%$ \\
\hline Norte & 7 & 1 & $14,3 \%$ \\
\hline TOTAL & $\mathbf{3 8}$ & $\mathbf{1 5}$ & $\mathbf{3 9 , 5 \%}$ \\
\hline
\end{tabular}

Fonte: os Autores.

Os dados mostrados anteriormente indicam que a maioria dos RI em funcionamento encontram-se no Nordeste, seguido das Regiões Sul e Sudeste com o mesmo quantitativo, a Região Centro-Oeste e, por fim, o Norte. Cabe mencionar também que a Região Sudeste possui 
um número comparativamente menor que outras regiões, um resultado que surpreende, haja vista que o IFSP pertence à Rede Sudeste de Repositórios Institucionais ${ }^{5}$. Pode-se deduzir da Tabela 1 que a maioria dos IF não apresenta RI, ou seja, 23 IF (60,5\%) ainda não possuem RI em funcionamento, o que indica a necessidade de um esforço por parte da gestão desses Institutos Federais para proceder com um planejamento e efetivar a implementação de seus RI, de modo a auxiliar e facilitar o acesso e o uso das produções científicas e acadêmicas nesses Institutos.

Dos Institutos que apresentam RI em funcionamento, conforme demonstra a tabela 2, a pesquisa identificou que $86,7 \%$ das instituições optaram pela utilização do software DSpace. Enquanto que dois IF utilizam outros softwares, sendo o Pergamum e open Monograph Press (OMP).

Tabela 2 - Softwares utilizados pelos IF para gerenciamento do RI

\begin{tabular}{cc}
\hline \multicolumn{1}{c}{ SOFTWARE } & QUANTITATIVO \\
\hline DSpace & 13 \\
Open Monograph Press (OMP) & 01 \\
Pergamum & 01 \\
\hline \multicolumn{2}{c}{ TOTAL } \\
\hline \multicolumn{2}{c}{ Fonte: os Autores. }
\end{tabular}

A partir dos dados constantes na tabela 2 buscou-se identificar, em síntese, as possíveis vantagens e desvantagens dos softwares que foram utilizados para implantação e gerenciamento dos RI nos respectivos IF, com o objetivo de compreender a escolha por determinado software em detrimento de outros. Constata-se por meio dos dados apresentados na Tabela 2 que há grande adesão dos IF pelo software DSpace, o que é possível inferir que há possíveis condições que favorecem a utilização desse software pelos IF. Garcia e Targino (2016), apontam que a condição de software adotado pelo IBICT impulsiona a utilização massiva do DSpace nos RI. Além do apoio institucional do IBICT essas autoras destacam que o DSpace:“[...] preserva e disponibiliza em regime de Acesso Aberto conteúdos digitais, tais como imagem, em movimento ou não, textos e rede de dados, é um dos softwares com condições mais propícias de preservação e acesso aos documentos armazenados”. (GARCIA; TARGINO, 2016, p. 160).

\footnotetext{
5 Informação disponível em: https://www.arca.fiocruz.br/bitstream/icict/46000/2/Relat\%C3\%B3rio_Final_Atividades_Rede_Sudeste_Reposit \%C3\%B3rios_Institucionais_2020.pdf. Acesso em 04 jun. 2021.
} 
Ademais, por se tratar de um software open source, a plataforma do DSpace permite aos desenvolvedores a possibilidade de customizá-lo, fazendo adaptações em seu código-fonte, além de sua distribuição ser gratuita (FERNANDES, 2018). O DSpace tem sido a plataforma mais utilizada entre os repositórios presentes no mundo, visto que em seu website consta que mais de 1.000 organizações e instituições utilizam esse software em seus repositórios. (FERNANDES, 2018).

Quanto ao uso do software Pergamum para gerenciamento de RI é necessário mencionar que esse é um software proprietário para gestão de bibliotecas (SCHIESSL; BRASILEIRO; SHINTAKU, 2020), que foi desenvolvido pela Associação Paranaense de Cultura e, atualmente, é gerenciado pela Assessoria de Tecnologia da Pontifícia Universidade Católica do Paraná (PUC-PR) (PERGAMUM, 2021). Esse sistema é avaliado com uma ótima aceitação no mercado, sendo comercializado a aproximadamente 600 instituições em nosso país, porém a sua customização é considerada difícil a cada instituição cliente (SILVA; OTTONI; SILVA, 2020). Ademais, por ser um software comprado, ao surgirem problemas no sistema a instituição contratante necessita entrar em contato com o suporte técnico do Pergamum, e aguardar um período para a resolução do problema (SILVA; CONCEIÇÃO; BRAGA, 2004).

O Open Monograph Press, por sua vez, “[...] é uma ferramenta livre, de código aberto, desenvolvida pelo Public Knowledge Project (PKP) para apoiar a atividade de editoração de livros, tanto digitais quanto impressos, preferencialmente em acesso aberto". (SHINTAKU; BRITO, 2019, p. 18). Atualmente, o OMP é um dos softwares apoiados pelo IBICT para a gestão de periódicos eletrônicos (IBICT, 2021). Nesses termos, observa-se que essa ferramenta é voltada para editoração de livros digitais ou físicos, bem como dá suporte à gestão de periódicos eletrônicos. Como dificuldade apresentada destaca-se que o OMP requer algum conhecimento técnico da parte de TI, o que poderá sobrepujar as competências dos profissionais de edição de livros. Além desse aspecto, Andrade e Araújo (2016) afirmam que há pouca adesão e utilização do software OMP pelas editoras universitárias brasileiras. De acordo com esses autores os principais aspectos que podem dificultar a utilização do OMP são dificuldades de uso, dificuldades técnicas de instalação do software, morosidade das editoras universitárias ou a estagnação imposta pelos processos burocráticos das universidades públicas.

Ainda sobre os dados informados na Tabela 2, cumpre mencionar que há a possibilidade de eles serem ratificados e/ou atualizados por meio do Censo anual da Educação Superior 2019 
(CenSup). Esse censo é realizado pelo Inep, de caráter declaratório e participação obrigatória de todas as Instituições de Ensino Superior (IES) cadastradas no sistema e-MEC.

Isto porque no CenSup de 2019 constatou-se o seguinte item de questionamento às IES: “Possui Repositório Institucional?" (INEP, 2019), com alternativas de respostas sim ou não, constante na aba Informações Adicionais da Biblioteca, conforme a Figura 1.

Figura 1 - Registro de documento com destaque para o item RI no Censo Superior 2019

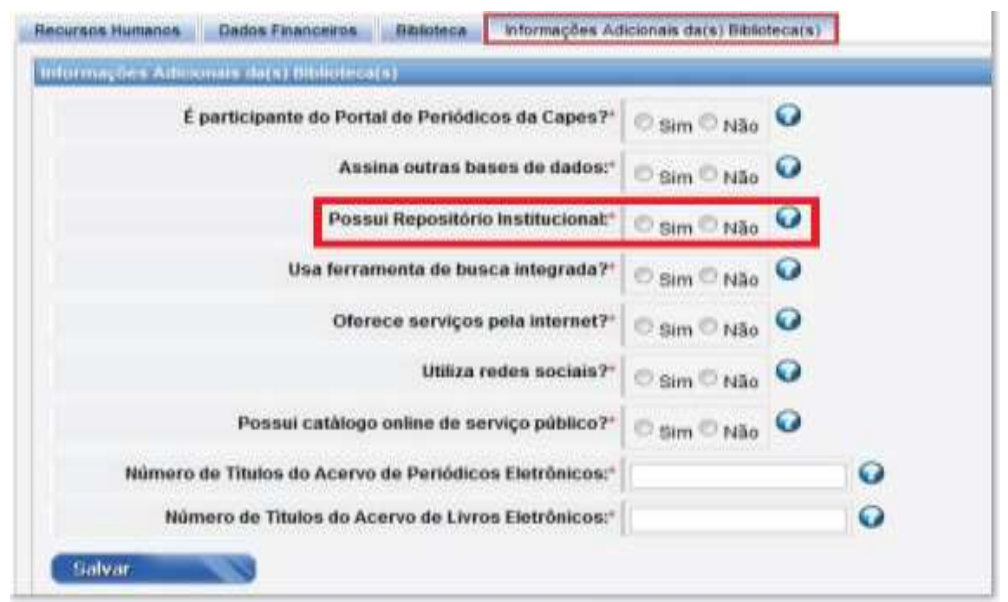

Fonte: (Inep, 2019, p. 21).

Assim, quando forem divulgadas as estatísticas do censo da educação superior 2019, prevista para acontecer em novembro de 2020, será possível realizar um comparativo desta pesquisa com os dados apresentados no CenSup quanto às instituições de ensino que possuem RI, em especial os IF.

Quanto à iniciativa para que o item sobre RI constasse no CenSup 2019, a informação é de que o questionário relativo à biblioteca foi feito em parceria com a Comissão Brasileira de Bibliotecas Universitárias (CBBU), segundo informado pelo Inep via e-mail no dia 14 de abril de 2020, os profissionais bibliotecários que colaboraram indicaram as informações relevantes que poderiam constar na avaliação das bibliotecas, apontando que não havia a opção para registrar a informação sobre os RI.

Após a divulgação dos dados referentes ao CenSup 2019, as informações coletadas junto às instituições de ensino superior sobre RI passarão a figurar como estatísticas oficiais da educação superior, o que poderá indicar quais instituições possuem RI e as que ainda necessitam implantar essa ferramenta tecnológica que visa democratizar o acesso à informação científica mundialmente. 


\section{Considerações finais}

O estudo apresentado mostra que os Institutos Federais têm se mobilizado e dado um importante passo para inserirem-se no movimento da Ciência Aberta, mais especificamente com relação às estratégias de democratização do acesso à produção científica por meio da implantação de Repositórios Institucionais. Isto porque dos 38 IF que compõem a Rede Federal, 15 instituições já implantaram seus RI, garantindo o acesso às suas produções desenvolvidas pela comunidade de estudantes e servidores.

No entanto, observa-se que a partir da ausência de uma legislação nacional que estabeleça os procedimentos de publicização da produção científica pelas IES, compreendidos nesse caso os IF, ainda podem ser encontradas barreiras quanto aos métodos e práticas para o alcance desta finalidade. Para além disso, é essencial que as instituições compreendam a necessidade de tornar público e acessível o que tem sido financiado por meio de recursos públicos, pois esta é uma forma de prestar contas ao que tem sido investido nessas instituições, principalmente em fomentos específicos para a realização de pesquisas.

Com relação aos softwares utilizados para a disponibilização das produções científicas, destaca-se o DSpace, sendo gratuito e de código aberto. No entanto, mesmo com a facilidade de acesso ao recurso tecnológico, algumas instituições relataram como principal dificuldade na implantação de seus repositórios a ausência de suporte técnico em Tecnologia da Informação (TI) nos IF para a customização do software.

Mesmo enfrentando essa dificuldade, a pesquisa mostrou que alguns Institutos Federais formalizaram comissões para iniciarem os estudos preliminares necessários ao desenvolvimento e implementação de repositórios em suas instituições. Além disso, é importante reforçar que 15 IF estão em fase de implantação de seus repositórios, o que demonstra o interesse dessas instituições em contribuir para reunir em um único local a produção acadêmica e científica produzida por sua comunidade.

As análises aqui apresentadas buscaram mostrar um panorama da implantação dos RI no âmbito dos Institutos Federais. Assim, compreende-se que esta pesquisa pode contribuir com o desenvolvimento de novos estudos no âmbito da Rede Federal de Educação Profissional, Científica e Tecnológica, relacionados à gestão, metadados, arquitetura da informação e usabilidade dos RI. Por fim, recomenda-se aos institutos que estão em fase de planejamento de 
seus RI que busquem parcerias junto aos IF com repositórios já implantados para obter apoio e auxílio no desenvolvimento de suas atividades em benefício da Ciência Aberta.

\section{Referências}

ALVES, Virgínia. Informação em Biblioteconomia: o livre acesso nas universidades federais. Curitiba: Appris, 2017.

ANDRADE, Robéria de Lourdes de Vasconcelos; ARAÚJO, Wagner Junqueira de. Aplicação do Open Monograph Press por editoras brasileiras. In: ENCONTRO NACIONAL DE PESQUISA EM CIÊNCIA DA INFORMAÇÃO, 17., 2016. Pôster... Bahia: ENANCIB, 2016. Disponível em:

http://www.ufpb.br/evento/index.php/enancib2016/enancib2016/paper/viewFile/3646/2493.

Acesso em: 30 maio 2021.

BRASIL. Câmara dos Deputados. Regimentoi, estabelecido pela Resolução no 17, de 1989. Brasília, 1989. Disponível em:

https://www2.camara.leg.br/legin/fed/rescad/1989/resolucaodacamaradosdeputados-17-21setembro-1989-320110-normaatualizada-pl.html. Acesso em: 30 jun. 2006.

BRASIL. Câmara dos Deputados. Projeto de Lei no 1120/2007. Brasília, 2007. Disponível em: https://www.camara.leg.br/proposicoesWeb/fichadetramitacao?idProposicao=352237. Acesso em: 29 ago. 2020.

BRASIL. Lei $\mathbf{n}^{\mathbf{0}}$ 11.892, de 29 de dezembro de 2008. Institui a Rede Federal de Educação Profissional, Científica e Tecnológica, cria os Institutos Federais de Educação, Ciência e Tecnologia, e dá outras providências. Brasília, DF: Presidente da República, [2008]. Disponível em: http://www.planalto.gov.br/ccivil_03/_ato2007-2010/2008/lei/111892.htm. Acesso em: 12 maio 2020.

BRASIL. Lei $\mathbf{n}^{\mathbf{0}}$ 12.527, de 18 de novembro de 2011. Regula o acesso a informações previsto no inciso XXXIII do art. $5^{\circ}$, no inciso II do $\S 3^{\circ}$ do art. 37 e no $\S 2^{\circ}$ do art. 216 da Constituição Federal; altera a Lei $n^{\circ} 8.112$, de 11 de dezembro de 1990; revoga a Lei $n^{\circ}$ 11.111, de 5 de maio de 2005, e dispositivos da Lei no 8.159, de 8 de janeiro de 1991; e dá outras providências. Brasília, DF: Presidente da República, [2011]. Disponível em: http://www.planalto.gov.br/ccivil_03/_Ato2011-2014/2011/Lei/L12527.htm. Acesso em: 28 maio 2020.

BRASIL. Senado Federal. Projeto de Lei do Senado no 387/2011. Brasília, 2011. Disponível em: https://www25.senado.leg.br/web/atividade/materias/-/materia/101006. Acesso em: 29 ago. 2020.

BRASIL. Câmara dos Deputados. Projeto de Lei no 6702/2013. Brasília, 2013. Disponível em: https://www.camara.leg.br/proposicoesWeb/fichadetramitacao?idProposicao=599605. Acesso em: 29 ago. 2020. 
BRASIL. Senado Federal. Projeto de Lei do Senado no 6473/2019. Brasília, 2019.

Disponível em: https://www25.senado.leg.br/web/atividade/materias/-/materia/140248. Acesso em: 29 ago. 2020.

CERRAO, Natalia Gallo; CASTRO, Fabiano Ferreira de. Repositórios institucionais das universidades federais brasileiras: análise da representação da informação. Informação \& Tecnologia, João Pessoa, v. 5, n. 1, p. 92-104, 2018. Disponível em: https://brapci.inf.br/index.php/res/v/110392. Acesso em: 18 jan. 2020.

CORREAA, Tiago Silva. A produção técnica na Universidade Federal de São Carlos: identificação para comunicação no repositório institucional. 2017. 85 f. Dissertação (Mestrado em Ciência, Tecnologia e Sociedade) - Universidade Federal de São Carlos. Centro de Educação e Ciências Humanas. São Carlos, SP, 2017. Disponível em: https://repositorio.ufscar.br/handle/ufscar/8866. Acesso em: 18 jul. 2020.

FERNANDES, W. M. Encontrabilidade da informação no repositório institucional da Unesp: um estudo de eye tracking em dispositivos móveis. 2018. 116 f. Dissertação (Mestrado em Ciência da Informação) - Universidade Estadual Paulista, Faculdade de Filosofia e Ciências, Marília, 2018. Disponível em:

https://repositorio.unesp.br/handle/11449/154361. Acesso em: 30 maio 2019.

FRETES, Cristiano Hass; SILVA, Lucas Lourenço. Desenvolvimento do RIF: repositório institucional de produções científicas e intelectuais do IFMS. 2019. $21 \mathrm{f}$. Trabalho de Conclusão de Curso (Curso Técnico em Informática) - Instituto Federal de Educação, Ciência e Tecnologia de Mato Grosso do Sul, campus Ponta Porã, Ponta Porã, 2019.

GARCIA, Joana Coeli Ribeiro; TARGINO, Maria das Graças. Fontes de informação ganham adesão nos repositórios institucionais. In: TOMAÉL, Maria Inês; ALCARÁ, Adriana Rosecler. (org.). Fontes de informação digital. Londrina: Eduel, 2016. p. 147-174.

GRÁCIO, José Carlos Abbud. Preservação digital na gestão da informação: um modelo processual para as instituições de ensino superior. São Paulo: Cultura Acadêmica, 2012. Disponível em:

https://repositorio.unesp.br/bitstream/handle/11449/113727/ISBN9788579833335.pdf?sequen

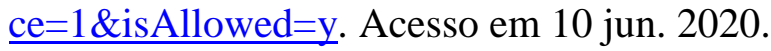

IBICT. Sistema para construção de repositórios institucionais digitais (DSpace). Brasília, Disponível em: https://ibict.br/tecnologias-para-informacao/dspace. Acesso em: 12 jun. 2020.

IBICT. Softwares apoiados pelo Ibict lançam nova versão disponível gratuitamente. IBICT, 2021. Disponível em: https://ibict.br/sala-de-imprensa/noticias/item/2687-softwaresapoiados-pelo-ibict-lancam-nova-versao-disponivel-gratuitamente. Acesso em 30 maio 2021.

IFMS. Boletim de serviço. ed. 65/2019. Campo Grande, 2019. Disponível em: https://suap.ifms.edu.br/bse/visualizar_boletim/97/. Acesso em: 17 ago. 2020.

INEP. Instrumento de avaliação de cursos de graduação presencial e a distância: reconhecimento, renovação de reconhecimento. Brasília, 2017. Disponível em: https://download.inep.gov.br/educacao_superior/avaliacao_cursos_graduacao/instrumentos/20 17/curso_reconhecimento.pdf. Acesso em: 12 nov. 2020. 
INEP. Manual de preenchimento do Censo da Educação Superior 2019: módulo Instituição de Educação Superior (IES). Brasília, 2019. Disponível em: https://download.inep.gov.br/educacao_superior/censo_superior/questionarios_e_manuais/20 19/Modulo_IES.pdf. Acesso em: 12 abr. 2020.

MOURA, Dante Henrique; LIMA FILHO, Domingos Leite; SILVA, Mônica Ribeiro. Politecnia e formação integrada: confrontos conceituais, projetos políticos e contradições históricas da educação brasileira. Revista Brasileira de Educação, [s.l.], v. 20, n. 63, p. 1057-1080, dez. 2015. Disponível em: http://dx.doi.org/10.1590/s1413-24782015206313. Acesso em: 16 out. 2019.

PERGAMUM: informações gerais. Paraná, 2021. Disponível em: http://www.pergamum.pucpr.br/pergamum. Acesso em: 23 fev. 2021.

PINTO, Adélia de Moraes; MENDONÇA, Dóris Campos; DANIN, Gisela Fernanda Monteiro; RODRIGUES, Andreia Cristina da Paixão; BERRÍO-ZAPATA, Cristian. Panorama dos repositórios institucionais nos Institutos Federais de Educação, Ciência e Tecnologia do Brasil. Ciência da Informação, v. 48, n. 3, 20 mar. 2019. Disponível em: http://revista.ibict.br/ciinf/article/view/4910. Acesso em: 20 maio 2020.

PORTO, Vera Lucia Solano Feitosa. Proposta de implantação de Repositório Institucional no Campus Campo Grande do IFMS: um estudo de caso. 2016. 39 f. Monografia (Graduação em Biblioteconomia) - Instituto de Ensino Superior da Funlec - IESF, Campo Grande, 2016.

SANTOS, Davilene Souza; ROSA, Flávia Goulart Mota Garcia. O movimento de Acesso Aberto e a UFBA: dez anos de implantação do repositório institucional. PontodeAcesso, Salvador, v. 14, n. 1, p. 97-116, abr. 2020. Disponível em: https://periodicos.ufba.br/index.php/revistaici/article/view/36682. Acesso em 01 jun. 2021.

SCHIESSL, Ingrid Torres; BRASILEIRO, Ítalo Barbosa; SHINTAKU, Milton. A implantação do software Koha na Biblioteca Graciliano Ramos da Escola Nacional de Administração Pública. Informação@Profissões, Londrina, v. 9, n. 2, p. 218-239, jul./dez. 2020. Disponível em:

http://www.uel.br/revistas/uel/index.php/infoprof/article/view/40387/pdf_1. Acesso em: 30 maio 2021.

SETENARESKI, Ligia Eliana; SHIMA, Walter; SUNYE, Marcos Sfair. A dinâmica competitiva do mercado mundial de publicações científicas: tendências e alternativas do acesso aberto. Curitiba: Appris, 2019.

SILVA, Chirley Cristiane Mineiro da; CONCEIÇÃO, Márcia Regina da; BRAGA, Roberto Carlos. Serviço de coleções especiais da Biblioteca Central da Universidade Federal de Santa Catarina: estágio curricular. Revista ACB, Florianópolis, v. 9, n. 1, p. 134-142, 2004. Disponível em: https://revista.acbsc.org.br/racb/article/view/403. Acesso em: 29 maio 2021.

SILVA, Fátima Santana; OTTONI, Heloisa Maria; SILVA, Rita Miryam Leme. Software livre como alternativa de inovação na gestão dos serviços de biblioteca: a experiência do NIB 
do CBPF. Informação@Profissões, Londrina, v. 9, n. 2, p. 92-115, 2020. Disponível em:https://brapci.inf.br/index.php/res/v/150797. Acesso em: 30 maio 2021.

SILVA, Terezinha Elisabeth da; ALCARÁ, Adriana Rosecler. Acesso aberto à informação científica: políticas e iniciativas governamentais. Informação \& Informação, Londrina, v. 14, n. 2, p. 100-116, jul./dez., 2009. Disponível em:

http://www.uel.br/revistas/uel/index.php/informacao/article/view/4817. Acesso em 17 jul. 2020.

SHINTAKU, Milton; BRITO, Ronnie Fagundes de. Guia de usuário do OMP: sistema de editoração eletrônica de livros e monografias. Brasília: IBICT; Curitiba: PUCPRESS, 2019. Disponível em: https://pucpress.pucpr.br/index.php/pucpress/catalog/view/130/159/668-1. Acesso em 23 fev. 2021.

TOMAÉL, Maria Inês (org.). Compartilhamento da informação. Londrina: Eduel, 2012.

WEITZEL, Simone da Rocha. O mapeamento dos repositórios institucionais brasileiros: perfil e desafios. Encontros Bibli: revista eletrônica de Biblioteconomia e Ciência da informação, Florianópolis, v. 24, n. 54, p. 105-123, jan./abr. 2019. Disponível em:

https://periodicos.ufsc.br/index.php/eb/article/view/1518-2924.2019v24n54p105/38092.

Acesso em: 17 jul. 2020. 